Research Article

\title{
Physicochemical and Mechanical Characterization of Raffia vinifera Pith
}

\author{
N. R. Sikame Tagne $\mathbb{D}^{1,{ }^{1,2,3,4}}$ T. E. Mbou, ${ }^{1,4}$ O. Harzallah, ${ }^{5,6}$ D. Ndapeu, ${ }^{1,2,3,4}$ W. Huisken (D), ${ }^{1,4}$ \\ D. Nkemaja, ${ }^{1,4}$ E. Njeugna, ${ }^{1,4}$ M. Fogue, ${ }^{2,3}$ and J-Y. Drean ${ }^{5,6}$ \\ ${ }^{1}$ Mechanics and Adapted Materials Laboratory (LAMMA), ENSET-University of Douala, Douala, Cameroon \\ ${ }^{2}$ Research Unit in Engineering of Industrial Systems and the Environment (UR-ISIE), IUT/FV Bandjoun-University of Dschang, \\ Dschang, Cameroon \\ ${ }^{3}$ Research Unit in Mechanics and Modeling of Physical Systems (UR-2MSP), Faculty of Science-University of Dschang, \\ Dschang, Cameroon \\ ${ }^{4}$ Mechanics Laboratory (LM), ENSET-University of Douala, Douala, Cameroon \\ ${ }^{5}$ Université de Haute-Alsace, LPMT UR 4365, F-68100 Mulhouse, France \\ ${ }^{6}$ Université de Strasbourg, Strasbourg, France
}

Correspondence should be addressed to N. R. Sikame Tagne; sikamenic@yahoo.com

Received 3 September 2020; Revised 18 November 2020; Accepted 3 December 2020; Published 16 December 2020

Academic Editor: Baozhong Sun

Copyright (c) 2020 N. R. Sikame Tagne et al. This is an open access article distributed under the Creative Commons Attribution License, which permits unrestricted use, distribution, and reproduction in any medium, provided the original work is properly cited.

\begin{abstract}
In this paper, the physicochemical and mechanical properties of Raffia vinifera pith (RVP) are discussed. Microscopic observations have shown that the structure of the RVP is similar to that of a composite consisting of natural fibers. The effective area ratio of Raffia vinifera (RV) fibers was evaluated along the raffia stem using ImageJ software, and it decreases from the periphery to the center. Energy dispersion spectrometer (EDS) analysis shows that RVP is essentially composed of carbon and oxygen. Densities of RVP and its matrix were determined using Archimedes' principle and law of mixtures, respectively; from the results obtained, they can be considered as one of the lightest materials. Young's modulus of RVP has been obtained from tensile and bending tests, while that of matrix has been obtained using the law of mixtures during tensile tests. RVP has better specific properties, and the results of the matrix properties show that we can easily select another matrix which has better properties than the case studied during the elaboration of composites.
\end{abstract}

\section{Introduction}

Waste management in recent years has led researchers to take an interest in the development of biodegradable materials for the emergence of biodegradable composites based on natural fibers [1-3]. Indeed, works have been carried out on plant fibers through treatments to replace synthetic fibers in composites materials [4]. Raffia vinifera pith (RVP) is a material from the stem of Raffia vinifera (RV) belonging to the Arecaceae family according to the authors of $[5,6]$. This plant mostly grows in marshy areas in Asia, South America, and tropical zone in Africa, especially in Cameroon. The RVP and RV stem are used by the populations of these regions as a raw material in the realization of structures (ceilings) and handicrafts such as baskets and mats, according to Sikame et al. [7].

Scientific works have been carried out on RV fibers. The density, the water absorption rate, and the diffusion coefficient were studied in the kinetics of water absorption and drying of RV fibers from the stem, as studied by the authors of [8-10]. In addition, the effective diffusion coefficient of the RVP along the stem was also determined in the kinetics of water absorption [11]. Mechanically, studies on the delayed behavior of RV stem versus load and temperature were performed, which resulted in the determination of Burger model parameters unlike those of Schapery, by the 
authors of [6, 12-15]. Also, Young's modulus of the fiber along the RV stem and its evolution has been evaluated [16]. Similarly, the study of creep/recovery behavior has enabled to propose a rheological model and to determine the viscoelastic parameters of RV fibers [7]. Finally, from the thermal point of view, the thermal conductivity of RVP has been determined $[17,18]$.

Considering the works carried out so far on the RV, we have noticed that it has interesting properties, although products from RVP such as baskets used in transportation of livestock and agricultural products deteriorate rapidly due to bad weather. One of the solutions could be the setting up of a biodegradable composite material based on RV fibers as reinforcement. In addition, we noted that pith from RV stem has undergone very little work. Extraction of RV fibers reveals the presence of other constituents, suggesting that the RVP itself is a macroscopic composite.

The objectives of this study are firstly to confirm after observations that RVP is a natural composite, secondly to determine some of its physicochemical and mechanical properties, and finally to characterize the natural matrix resulting from it (RVP). Such results may help in selecting the type of matrix to be used in biodegradable composite material making.

\section{Experimental}

2.1. Materials. The RVP samples used to perform the various tests had a width of $a \varepsilon[3.5 \mathrm{~mm}-8 \mathrm{~mm}]$, height $h \varepsilon[3.5 \mathrm{~mm}-8 \mathrm{~mm}]$, and length $L \varepsilon[85 \mathrm{~mm}-95 \mathrm{~mm}]$ and came from the twelve sampling zones of RV stem, as shown in Figure 1. RV stems were collected from the swampy areas around Fotso Victor University Institute of Technology in Bandjoun, Cameroon. A digital caliper of precision $0.001 \mathrm{~mm}$ was used to determine the dimensions of each sample.

The RVP cross-sectional images were observed using an optical microscope of 16x magnifications from the Laboratory of Textile Physics and Mechanics (LPMT) in Mulhouse, France. The study of the bulk density of RVP was carried out using a $0.001 \mathrm{~g}$ precision digital scale for the weighing of the samples.

Axial dynamic tensile and three-point bending tests were carried out using the MTS M/20 tensile machine at a speed of movement of the jaws of $5 \mathrm{~mm} / \mathrm{min}$ at the LPMT.

Approximately 25 samples were used in each study area for each parameter explored.

\subsection{Methods}

2.2.1. Determination of Surface Fractions. The determination of the surface fractions of RV fibers was made using images from various cross sections and ImageJ software. The surface fraction is calculated using the following equation:

$$
S_{f}=\frac{\sum_{i=1}^{n} S_{\mathrm{fi}}}{S_{\mathrm{RVP}}}
$$

where $S_{\mathrm{f}}, S_{\mathrm{RVP}}$, and $S_{f}$ are, respectively, the cross-sectional area of each fiber and RVP and the surface fraction of the RV fibers.
2.2.2. Determination of the Chemical Elements of RVP along the RV Stem. The chemical elements of RVP were determined using the JEOL scanning electron microscope (SEM) of the LPMT in Mulhouse based on the analysis of energy dispersion spectrometer (EDS). This approach has been applied in the evaluation of the chemical composition of certain natural fibers such as Passiflora foetida, Roselle, palm, or Carica papaya bark fibers by the authors of [19-22].

\subsubsection{Determination of Bulk Density}

(1) Case of RVP along the Stem. The bulk density of RVP was evaluated using the gravimetric method based on Archimedes' principle from ASTM-D3800-99 [23], also used for the determination of the density of kenaf or RV $[16,24]$. Equation (2) enables us to determine the density of the RVP:

$$
\rho_{\mathrm{RVP}}=\frac{m_{\mathrm{RVP}}}{V_{t}-\left(V_{i}+V_{\mathrm{nut}}+V_{p}\right)},
$$

where $V_{p}, V_{i}, V_{t}$, and $V_{\text {nut }}$, respectively, represent the paraffin, initial volume of the tube, the final volume of the tube, and the final volume of the nut with $V_{p}=\left(m_{t}-m_{\mathrm{RVP}}\right) / \rho_{p}$; then, $m_{\mathrm{RVP}}$ and $m_{t}$ are the respective masses of each sample of RVP and the sample RVP made up with paraffin, and finally $\rho_{p}$ is the density of paraffin, which was also applied to evaluate the density of oil palm fruits or RV fibers $[16,25]$.

(2) Case of the RVP Matrix. The RVP is a composite whose bulk density of fiber along the stem is known for each study area (twelve) and that of the natural matrix remains unknown. The bulk density of RVP considered here as composite is given by the law of mixtures in the following equation:

$$
\rho_{\mathrm{RVP}}=S_{f} \rho_{f}+\left(1-S_{f}\right) \rho_{m},
$$

where $\rho_{\mathrm{RVP}}, \rho_{f}$, and $\rho_{m}$ are, respectively, the densities of the RVP, the fiber, and the RVP matrix taken in each study area. Moreover, $S_{f}$ represents the surface fraction of fiber in a sample of RVP. This formula of equation (3) was used to evaluate the bulk density of polypropylene fiber composites [26].

Determination of the bulk density of the RVP matrix is performed using equation (4) obtained from equation (3):

$$
\rho_{m}=\frac{\rho_{\mathrm{RVP}}-S_{f} \rho_{f}}{\left(1-S_{f}\right)}
$$

2.2.4. Determination of Young's Modulus of RVP (Composite) by Tensile Test. The approach used in determining Young's modulus of RVP in the tensile test is the ASTM D 3822-01 [27] standard method. Data were obtained from the tensile test with an imposed speed of $5 \mathrm{~mm} / \mathrm{min}$, namely, the elongation $(\Delta l)$ as a function of the effort $(F)$ allowed us to find the strain $(\varepsilon)$ using equation (5), which was also used in mechanical characterization of RV fibers [16]: 


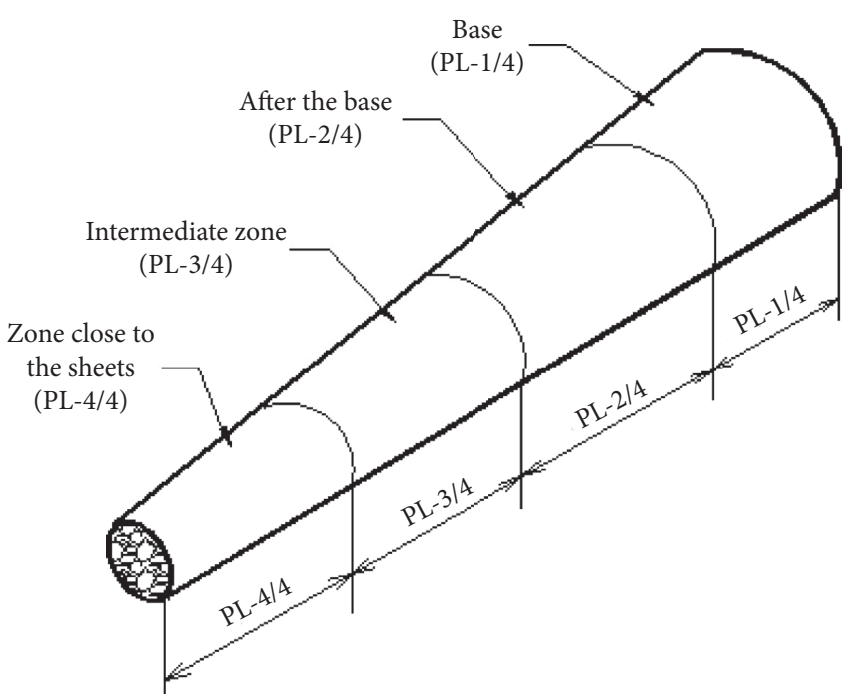

(a)

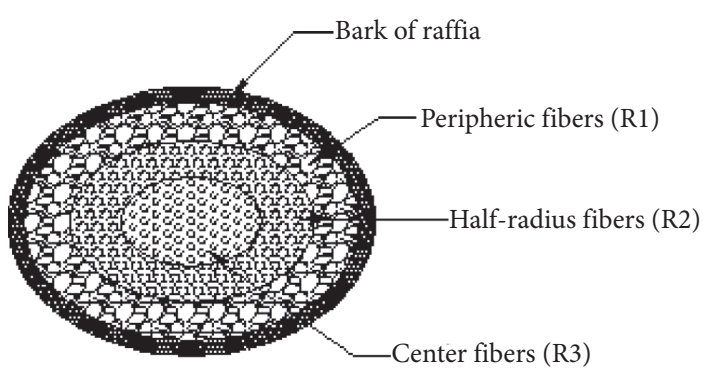

(b)

FIGURE 1: Location of fiber sampling areas along the RV stem: (a) longitudinal position; (b) cross section in a precise longitudinal position [10].

$$
\varepsilon=\frac{\Delta l}{l_{0}}
$$

where $l_{0}$ is the initial length of the specimen.

The stress $(\sigma)$ was calculated using equation (6), which was also used in determining the mechanical properties of sugarcane, coconut, or RV fibers [16, 28, 29]:

$$
\sigma=\frac{F}{S}
$$

where $S$ represents the cross section of the specimen. Young's modulus was considered to be the slope of regression line in the elastic domain of the stress-strain diagram plotted in MATLAB R2015a software.

\subsubsection{Determination of Young's Modulus of the Matrix from} $R V P$. The calculation of Young's modulus of the RVP matrix along the stem was made from Young's moduli of the RVP considered as the composite, and that of the RV fiber admitting the interface between the matrix and the fiber is perfect. By the law of mixtures of Young's modulus given in equation (7), also used for composites based on flax fibers $[30,31]$, we deduced Young's modulus of the matrix:

$$
E_{\mathrm{RVP}}=S_{f} E_{f}+\left(1-S_{f}\right) E_{m},
$$

where $E_{f}, E_{m}$, and $E_{\mathrm{RVP}}$, respectively, represent Young's moduli of the fiber, the matrix, and the RVP and $S_{f}$ represents the surface fraction of the fibers in a sample of RVP.

Equation (8) was obtained from equation (7) and is to calculate Young's modulus values of the matrix in each sampling zone:

$$
E_{m}=\frac{E_{\mathrm{RVP}}-S_{f} E_{f}}{\left(1-S_{f}\right)} .
$$

2.2.6. Calculation of the Tensile Strength of the Matrix from the RVP. The determination of the tensile strength of RVP matrix along the stem was made using RVP and RV fiber tensile strengths obtained graphically from experimental curves. From the law of mixtures of stress in equation (9), also used for composites based on flax fibers [31], we obtained the tensile strength of the RVP matrix:

$$
\sigma_{\mathrm{RVP}}=S_{f} \sigma_{f}+\left(1-S_{f}\right) \sigma_{m}
$$

where $\sigma_{f}, \sigma_{m}$, and $\sigma_{\mathrm{RVP}}$, respectively, represent the tensile strength of the RV fiber, the matrix, and the RVP and $S_{f}$ represents the surface fraction of the fibers in a sample of RVP.

Equation (10) was obtained from equation (9) to determine the tensile strength values of the RVP matrix in each sample area:

$$
\sigma_{m}=\frac{\sigma_{\mathrm{RVP}}-S_{f} \sigma_{f}}{\left(1-S_{f}\right)}
$$

\subsubsection{Determination of Young's Modulus of RVP (Composite)} by the Three-Point Bending Test. The evaluation of RVP Young's modulus using the three-point bending test was performed according to the ASTM D790-07 [32] standard method. The tests have been carried out using the MTS 20/M tensile machine set at a speed of $5 \mathrm{~mm} / \mathrm{min}$ for the displacement of the movable jaw with the adaptation of a threepoint bending device. From the bending force $F$ and the deflection $\Delta l$ data, we plotted the curve of the force with respect to the deflection. We know that equation (1) gives the expression of the deflection as a function of the bending force and it has been used for the evaluation of Young's modulus of some samples of wood or composites based on flax fibers [31, 33]. 


$$
\Delta l=\frac{F L^{3}}{48 E_{\mathrm{fl}} I},
$$

where $E_{\mathrm{fl}}$ and $I$, respectively, are Young's modulus in the bending test and the quadratic moment in the cross section of the specimen.

We can deduce Young's modulus of RVP in the bending test as the slope of the elastic zone of the curve of the pressure force with respect to the following equation:

$$
E_{\mathrm{fl}}=\frac{\alpha L^{3}}{48 I},
$$

where $\alpha=F / \Delta l$ is the slope of the curve and $I=\left(b h^{3} / 12\right)$ is the quadratic moment of the section.

Then,

$$
E_{\mathrm{fl}}=\frac{\alpha L^{3}}{4 h^{3}} .
$$

\section{Results and Discussions}

3.1. Determination of Surface Fractions of the RVP. Figures 2(a) and 2(b) show the cross section of a sample of RVP from the center and at the base (PL-1/4-R3) of the RV stem, respectively, from the optical microscope and ImageJ software. Similar approach of calculating the area fraction has been used to identify wood species by Gurau et al. [34] and for bacterial adhesion to polymeric substrates by Yuan et al. [35]. We observe the fibers and the material which makes it possible to organize them. This material gives shape to the RVP and also to the RV stem. It can be considered as the matrix of our sample.

Figure 3 illustrates the evolution of the surface fractions of the RV fibers in a sample of RVP. We notice that these values vary globally in the interval of $35.80 \%-54.50 \%$. They are smaller than those found on wood during the study of the surface fractions which varied between $26 \%$ and $74 \%$ by Poorter et al. [36] and from $20 \%$ to $74 \%$ by Ziemińska et al. [37].

Considering the obtained values, we observe that, at any longitude along the RV stem, the surface fraction of the RV fiber increases from the center to the periphery. However, if we are at any radial position, the variation of the surface fraction will not be significant. This can be justified by the fact that fiber is continuous from the base to the top of the stem and the plants are at maturity.

The surface fraction of the matrix constituting the pith can be deduced from the following formula:

$$
S_{m}=1-S_{f},
$$

where $S_{m}$ is the surface fraction of the RVP matrix. We noted that the surface fraction of the RVP matrix oscillates in between the interval of $45.50 \%-64.20 \%$. These values are close to the volume fraction assimilated to surface fraction in our case during the realization of natural fiber-reinforced polymer composites [38].
3.2. Determination of the Chemical Elements of the RVP along the Stem. Figures 4(a) and 4(b) highlight the structure of different chemical elements constituting the RVP. The atoms of carbon, oxygen, and silicon can be observed. Figures 5(a) and 5(b) show peaks emerging from the chemical elements contained in a RVP sample extracted from the $1 / 4$ center area, respectively, on the fiber/matrix boundary and on the matrix. We noted that each sample generally contains a majority of carbon followed by oxygen and then traces of silicon. Nevertheless, some areas of study show us the presence of calcium in a very small percentage, as shown in Table 1. Note also that, in the synthesis of the chemical elements of the sampling zones along the RV stem, the percentage of carbon is in between $51 \%$ and $57 \%$ while that of oxygen varies in the interval of $41 \%-48 \%$. Such an observation was also made for Roselle, palm, and hemp fibers $[20,39]$.

Finally, we notice the traces of calcium and silicon with mass percentages not exceeding $2.5 \%$.

\subsection{Determination of Bulk Density}

3.3.1. Case of the RVP. Figure 6 shows the evolution of the bulk density of the RVP along the stem. We noted that, in any transversal position, the bulk density evolves increasingly from the center to the periphery and in any position of the cross section of the stem and decreases from the base to the top of the stem.

We find that the values are between $0.116 \mathrm{~g} / \mathrm{cm}^{3}$ and $0.343 \mathrm{~g} / \mathrm{cm}^{3}$, and it is comparable to the bulk density of RV fibers which evolves from $0.128 \mathrm{~g} / \mathrm{cm}^{3}$ to $0.237 \mathrm{~g} / \mathrm{cm}^{3}$ during the study conducted by Sikame et al. [16]. The RVP can be considered as a light material.

3.3.2. Case of the RVP Matrix. The bulk density of the RVP matrix is evaluated using equation (4). Figure 7 shows the evolution of the bulk density along the RV stem. We noted also that the values increase from the center to the periphery at any cross section along the stem and they are between $0.1 \mathrm{~g} / \mathrm{cm}^{3}$ and $0.46 \mathrm{~g} / \mathrm{cm}^{3}$. The density of the matrix of RVP is less than that of polymer generally used as matrix during the elaboration of composite $[38,40]$. Then, we observed that the maximum values are at the base of the stem for the bulk density of RVP and its matrix.

By comparing them to the synthetic matrices given in Table 2, we found that they are the lightest bulk density.

3.4. Determination of Young's Modulus of RVP in Tensile Test. Figure 8 shows the curve of the stress with respect to the deformation of a sample of RVP from the zone (PL-1/4-R3). This curve has a linear tendency. This appearance was observed for all the samples tested and enables us to conclude that the RVP seems to be a fragile composite material. Young's modulus was obtained from the linear zone of the curve as they have been done for the RV fibers [16].

Figure 9 illustrates the evolution of Young's modulus in the tensile test along the twelve sampling zones of the RV 


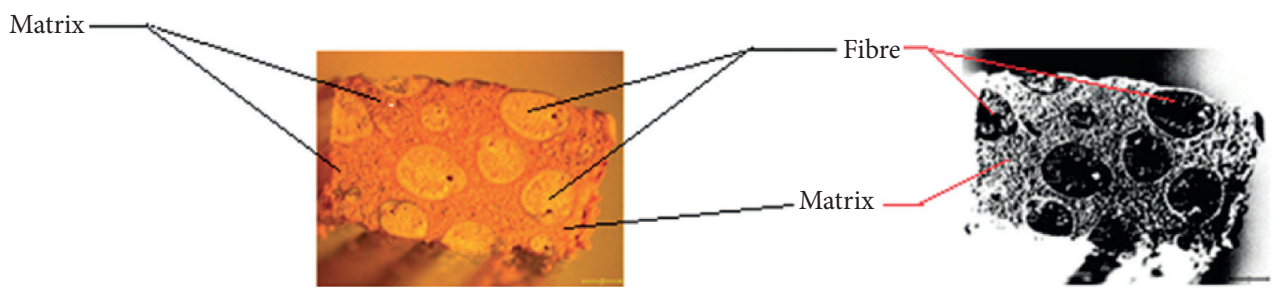

(a)

(b)

FIgUre 2: Cross section of a sample (PL-1/4-R3) of RVP. (a) Optical microscope (16x). (b) ImageJ.

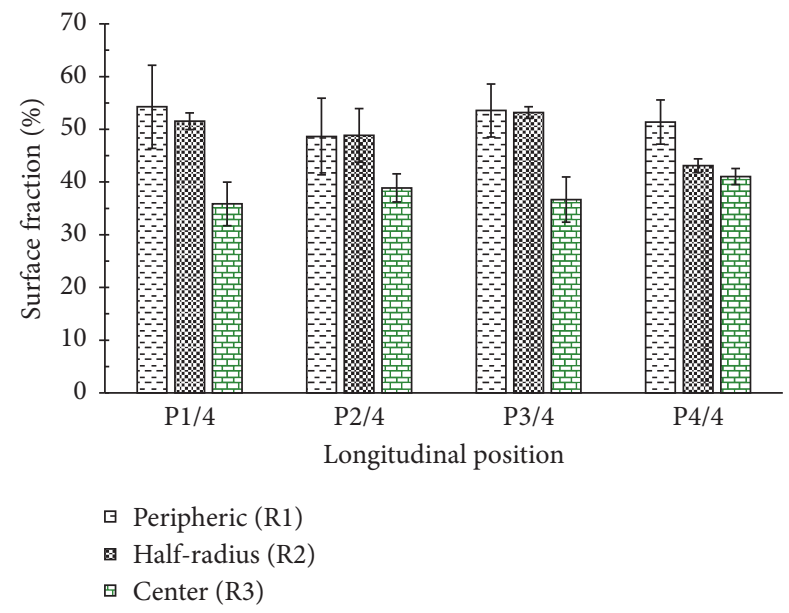

FIGURE 3: Synthesis of surface fractions of RV fibers along the RV stem.

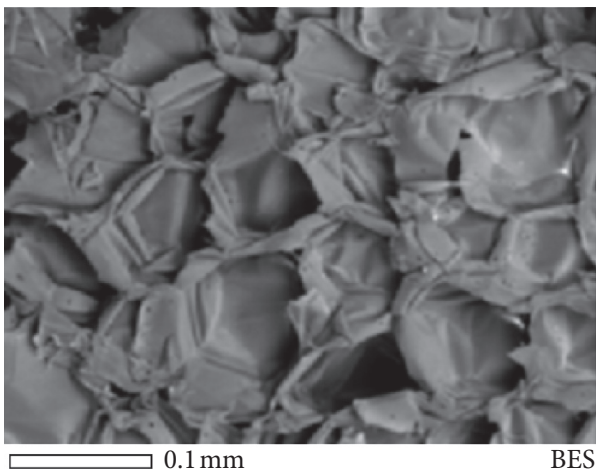

(a)

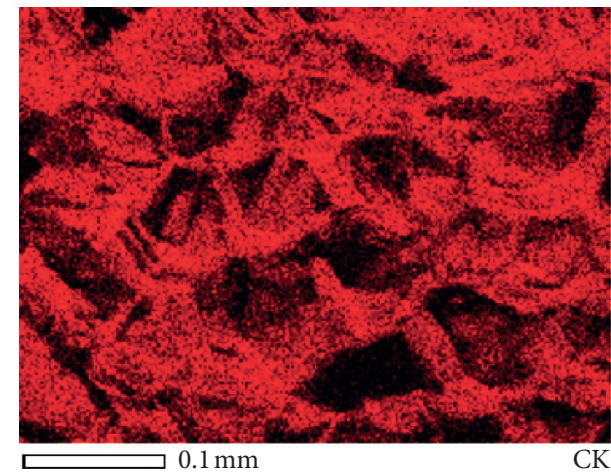

(b)

FIGURE 4: Chemical elements constituting the RVP: (a) carbon and (b) oxygen.

stem. We observe firstly that it increases from the center to the periphery in any cross section and secondly from the top towards the base of the stem when it is situated in a radial position. A similar result was found when studying the distribution of mechanical properties of RV fibers along the stem [16]. Finally, it appeared that Young's modulus of RVP is between $0.79 \mathrm{GPa}$ and $3.23 \mathrm{GPa}$. These values are close to those of wood species varying from $2.79 \mathrm{GPa}$ to $16.03 \mathrm{GPa}$ [40], which means the RVP can be resistant when used as raw material in building construction.

Furthermore, the tensile strength of RVP was determined by the curves in Figure 8 of the samples along the RV stem. It indicates that the values of this stress lie in the range of 11.7-44.5 MPa.

3.5. Determination of Young's Modulus of the Matrix from $R V P$. As shown in Figure 10, Young's modulus of RVP matrix increases from the center to the periphery in any transversal position along the stem. Similarly, it is observed that the zone with the highest Young's modulus is the base of the stem (PL-1/4). This remark is similar to that of RVP. It is in contradiction with the results of the work carried out on the mechanical characterization of RV fibers along the stem 


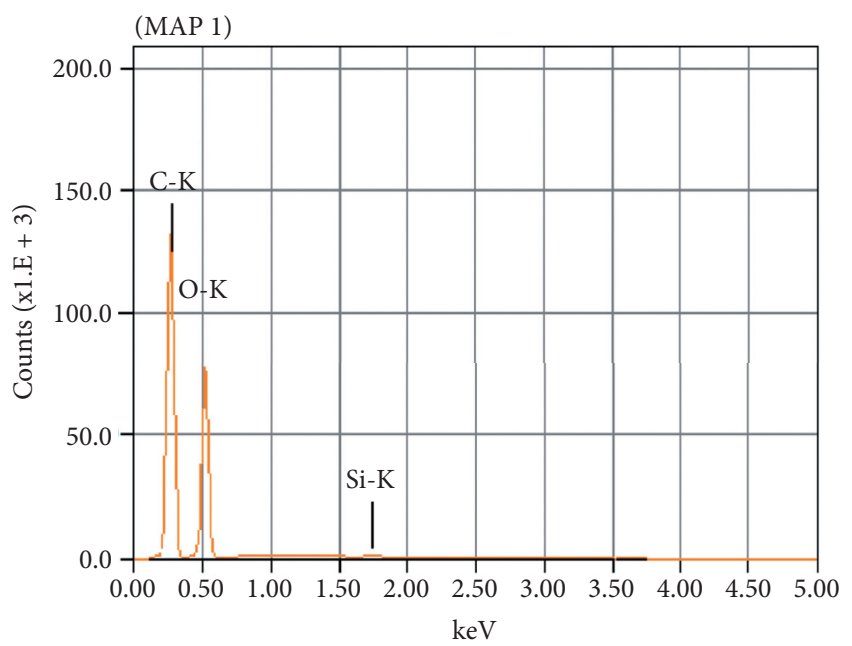

(a)

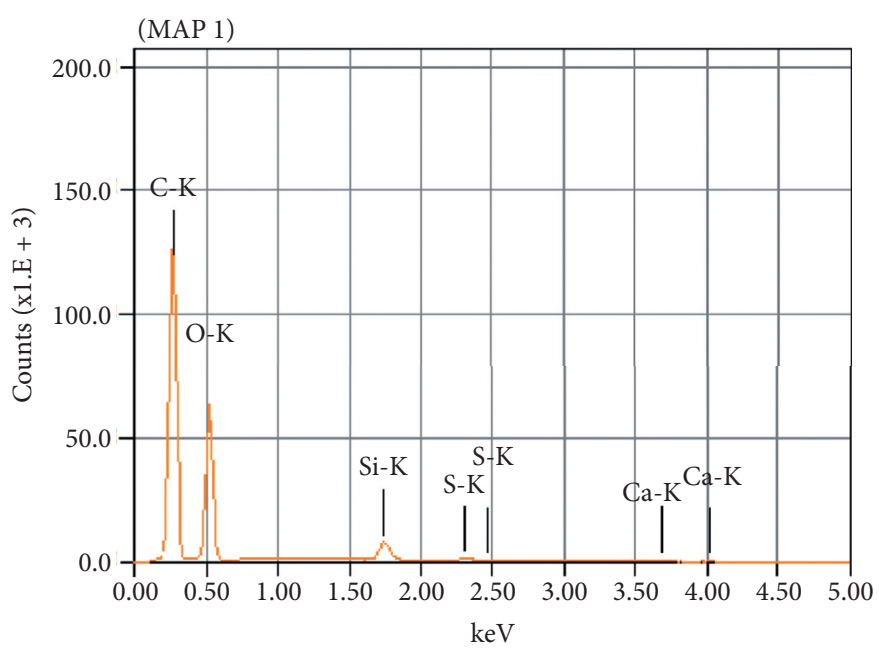

(b)

FIGURE 5: Energy dispersion spectrometer (EDS) of RVP of center position 1/4: (a) fiber/matrix border and (b) fiber.

TABLE 1: Summary of mass percentages of RVP chemical elements.

\begin{tabular}{|c|c|c|c|c|c|c|c|c|c|c|}
\hline \multirow{3}{*}{ Longitudinal position } & \multirow{3}{*}{ Chemical elements } & \multicolumn{9}{|c|}{ Radial position } \\
\hline & & \multicolumn{3}{|c|}{ Center (R3) } & \multicolumn{3}{|c|}{ Half-radius (R2) } & \multicolumn{3}{|c|}{ Peripheric (R1) } \\
\hline & & Fiber & Fiber/matrix & Matrix & Fiber & Fiber/matrix & Matrix & Fiber & Fiber/matrix & Matrix \\
\hline \multirow{4}{*}{ PL-1/4 } & $\mathrm{C}$ & 52.14 & 53.51 & 55.79 & 52.64 & 53.86 & 52.24 & 55.16 & 53.48 & 54.55 \\
\hline & $\mathrm{O}$ & 47.65 & 46.13 & 41.02 & 46.98 & 45.46 & 41.65 & 44.51 & 46.52 & 44.15 \\
\hline & $\mathrm{Si}$ & 0.21 & 0.36 & 2.16 & 0.38 & 0.67 & 5.53 & 0.33 & - & 0.67 \\
\hline & $\mathrm{Ca}$ & - & - & 0.65 & - & - & 0.58 & - & - & 0.63 \\
\hline \multirow{4}{*}{ PL-2/4 } & $\mathrm{C}$ & 51.12 & 53.42 & 50.76 & 51.46 & 51.48 & 50.41 & 51.73 & 50.07 & 51.78 \\
\hline & $\mathrm{O}$ & 48.88 & 46.14 & 47.37 & 48.17 & 47.97 & 46.91 & 48.27 & 49.78 & 47.02 \\
\hline & $\mathrm{Si}$ & - & 0.44 & 1.37 & 0.37 & 0.56 & 2.15 & - & 0.14 & 0.65 \\
\hline & $\mathrm{Ca}$ & - & - & 0.49 & - & - & 0.53 & - & - & 0.55 \\
\hline \multirow{4}{*}{ PL-3/4 } & $\mathrm{C}$ & 51.77 & 53.54 & 51.99 & 53.96 & 52.22 & 52.22 & 51.33 & 51.62 & 52.35 \\
\hline & $\mathrm{O}$ & 47.81 & 44.42 & 46.25 & 45.51 & 47.78 & 46.80 & 48.67 & 48.00 & 45.91 \\
\hline & $\mathrm{Si}$ & 0.42 & 1.39 & 1.10 & 0.52 & - & 0.43 & - & 0.39 & 1.19 \\
\hline & $\mathrm{Ca}$ & - & 0.65 & 0.66 & - & - & 0.55 & - & - & 0.56 \\
\hline \multirow{4}{*}{ PL- $4 / 4$} & $\mathrm{C}$ & 56.30 & 55.16 & 51.79 & - & 53.76 & 53.76 & 52.87 & 53.58 & 54.26 \\
\hline & $\mathrm{O}$ & 43.10 & 42.36 & 46.11 & - & 45.33 & 45.33 & 45.65 & 45.29 & 42.67 \\
\hline & $\mathrm{Si}$ & 0.61 & 2.01 & 1.49 & - & 0.28 & 0.28 & 1.01 & 0.75 & 0.77 \\
\hline & $\mathrm{Ca}$ & - & 0.47 & 0.61 & - & 0.63 & 0.63 & 0.46 & 0.39 & 0.59 \\
\hline
\end{tabular}

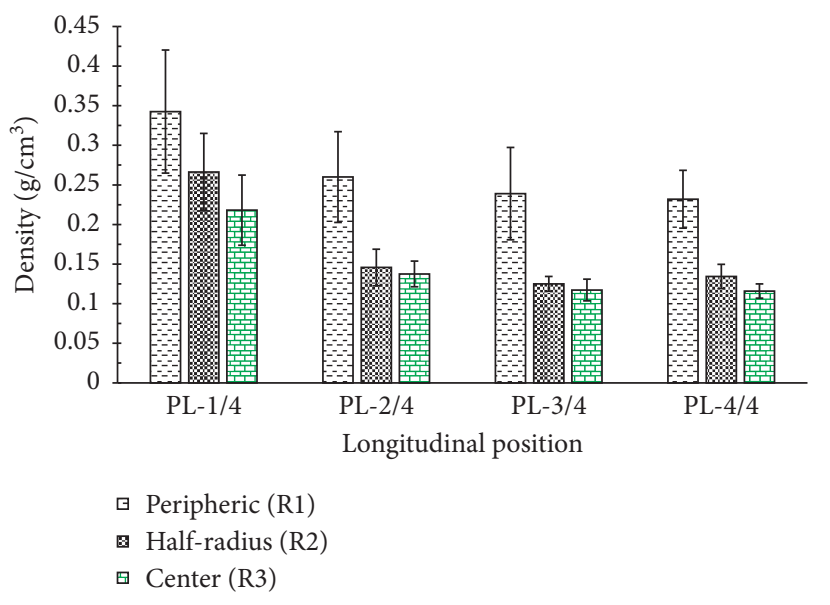

FIGURE 6: Evolution of the bulk density of the RVP along the stem.
[16]. The values of Young's modulus of the RVP matrix are in the range of $1.20-5.5 \mathrm{GPa}$ and are in the same order compared to those of some polymers [41, 42].

In addition, the tensile strength of RVP matrix and RV fiber was evaluated using equation (1). The values obtained are between $12.82 \mathrm{MPa}$ and 75.16 MPa.

3.6. Determination of Young's Modulus of RVP in Three-Point Bending Test. Figure 11 illustrates the force versus deflection curve of a RVP sample. Note that this curve has two zones, namely, a linear zone (I) and a nonlinear zone (II). To determine Young's modulus of the RVP samples from the bending tests, we used the linear part. This approach has been applied for the determination of Young's modulus of flax, abaca, or RV fibers [16, 43, 44]. 


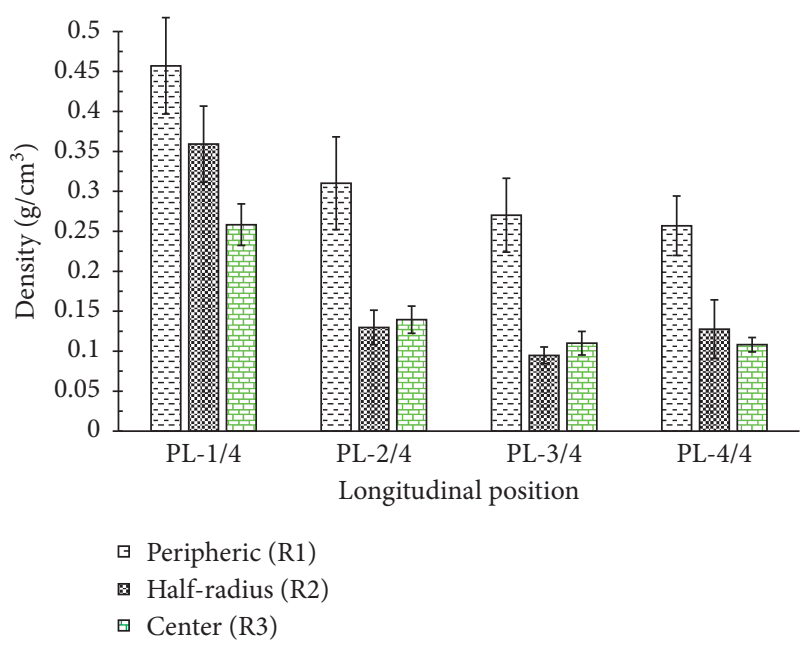

Figure 7: Evolution of the bulk density of the matrix from the RVP along the stem.

TABle 2: Synthesis of physicochemical and mechanical properties of some materials [38, 40-42, 45].

\begin{tabular}{|c|c|c|c|c|c|}
\hline Matrix type & $\begin{array}{l}\text { Density } \\
\left(\mathrm{g} / \mathrm{cm}^{3}\right)\end{array}$ & $\begin{array}{l}\text { Tensile strength in } \\
\text { tensile test }(\mathrm{MPa})\end{array}$ & $\begin{array}{l}\text { Young's modulus in } \\
\text { tensile test }(\mathrm{GPa})\end{array}$ & $\begin{array}{l}\text { Specific Young's modulus } \\
\text { in tensile test }\left(\mathrm{GPa} / \mathrm{g} / \mathrm{cm}^{3}\right)\end{array}$ & $\begin{array}{l}\text { Young's modulus in } \\
\text { bending test (GPa) }\end{array}$ \\
\hline Polyester & $1.2-1.5$ & $40-90$ & $2.0-4.50$ & $1.33-3.75$ & - \\
\hline Vinyl ester & $1.2-1.4$ & $69-83$ & $3.1-3.8$ & $2.21-3.16$ & - \\
\hline Epoxy & $1.1-1.4$ & $60-80$ & $2.00-6.00$ & $1.42-5.46$ & - \\
\hline Nylon 6 & $1.12-1.14$ & $43-79$ & 2.9 & $2.54-2.59$ & - \\
\hline Polypropylene & $0.899-0.92$ & $26-41.4$ & $0.95-1.77$ & $1.03-1.31$ & - \\
\hline Polystyrene & $1.04-1.06$ & $25-69$ & $4-5$ & $3.77-4.81$ & - \\
\hline Polyimide & $1.43-1.89$ & - & $3.10-4.90$ & $1.64-3.43$ & - \\
\hline Polyamide & 1.14 & $60-85$ & $1.2-2.5$ & $1.05-2.20$ & - \\
\hline Sindora sp. wood & 0.521 & - & - & - & $0.8-2.4$ \\
\hline Pinus chiapensis & $0.36-0.551$ & - & $2.56-10.19$ & $7.11-28.31$ & - \\
\hline $\begin{array}{l}\text { Pinus caribaea } \\
\text { bahamensis }\end{array}$ & $0.34-0.749$ & - & $2.79-13.80$ & $8.20-40.59$ & - \\
\hline $\begin{array}{l}\text { Gymnacranthera } \\
\text { eugenifolia wood }\end{array}$ & 0.580 & - & - & - & $0.9-1.6$ \\
\hline $\begin{array}{l}\text { Raffia vinifera pith } \\
\text { (RVP) }\end{array}$ & $0.11-0.35$ & $11.7-44.5$ & $0.79-3.23$ & $2.25-29.37$ & $1.02-4.20$ \\
\hline RVP matrix & $0.1-0.46$ & $12.82-75.16$ & $1.20-5.50$ & $2.60-55.00$ & - \\
\hline
\end{tabular}

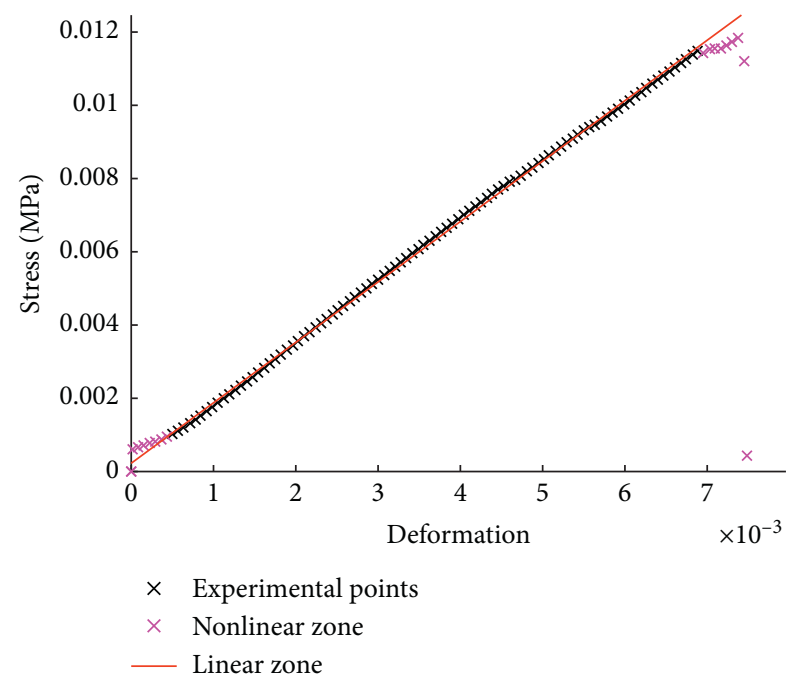

FIGURE 8: Curve of the stress as a function of the deformation of the specimen of the RVP of the zone (PL-1/4-R3) in the tensile test.
Similarly, Figure 12 shows the evolution of Young's modulus of RVP along the stem at the end of the three-point bending test. It is clear that Young's modulus evolves from the center to the periphery in any cross section along the stem. The values obtained are between $1.02 \mathrm{GPa}$ and $4.20 \mathrm{GPa}$, and the highest values are at the base of the stem (PL-1/4). They are more important than Young's modulus of some wood species [42].

Table 2 regroups the values of physical and mechanical properties of some polymers, wood species, and materials derived from the RV plant. We noted that Young's modulus is higher in flexion than in tensile tests. We observed that RVP has Young's modulus comparable to some wood varieties. Moreover, the specific mechanical properties show that RVP is more resistant than some wood species given in Table 2. Similarly, the RVP matrix has Young's modulus value in the same order as that of the polymer matrix. Also, it has one of the lowest densities, conferring its high specific mechanical properties. It emerges that the physical and 


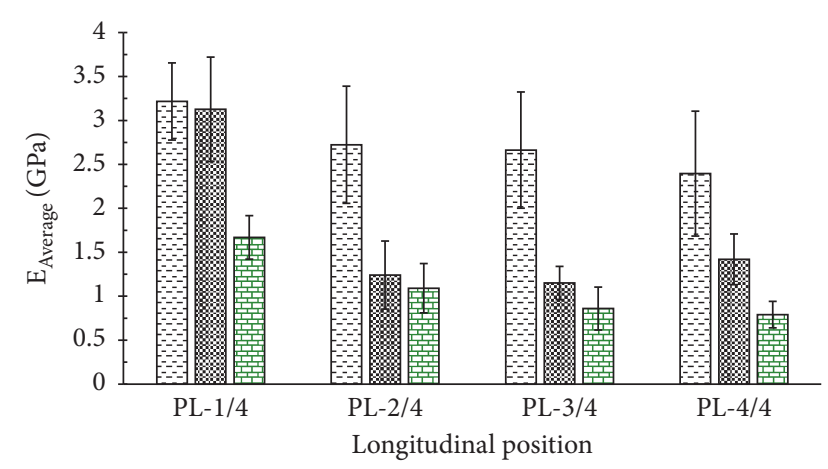

$$
\begin{aligned}
& \square \text { Peripheric (R1) } \\
& \text { H Half-radius (R2) } \\
& \square \text { Center (R3) }
\end{aligned}
$$

FIGURE 9: Distribution of Young's modulus in the tensile test of the RVP along the stem.

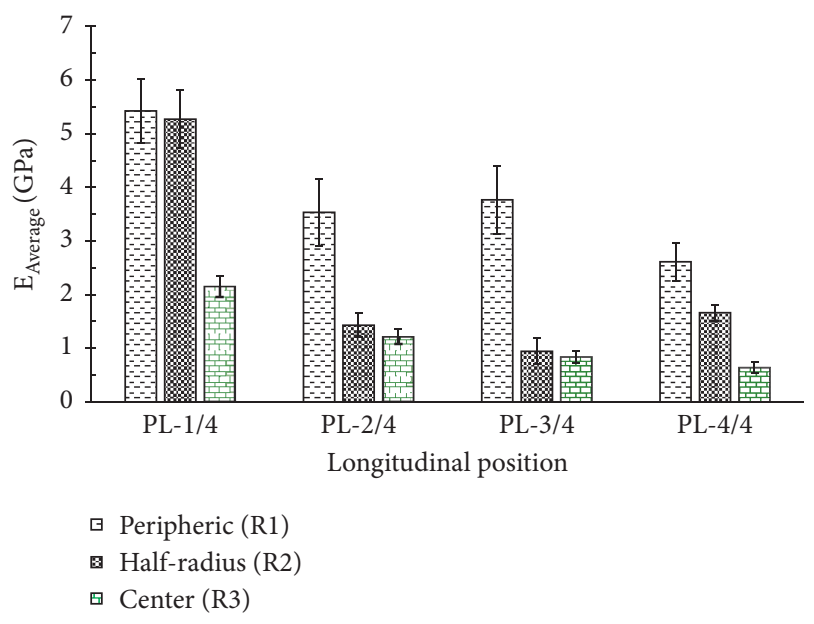

Figure 10: Distribution of Young's modulus in the tensile test of the RVP matrix along the stem.

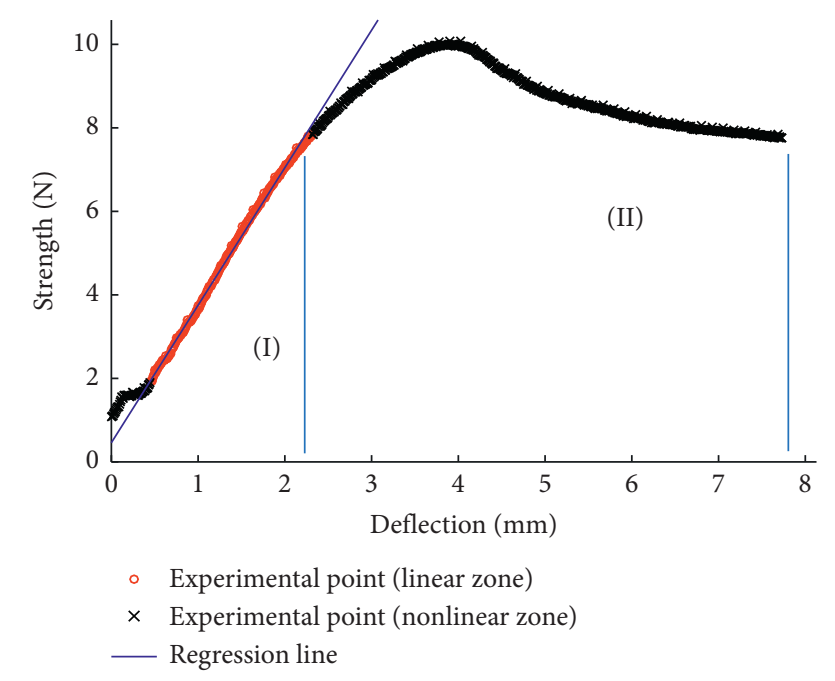

FIgURE 11: Force versus deflection curve for the three-point bending test of a RVP sample along the stem.

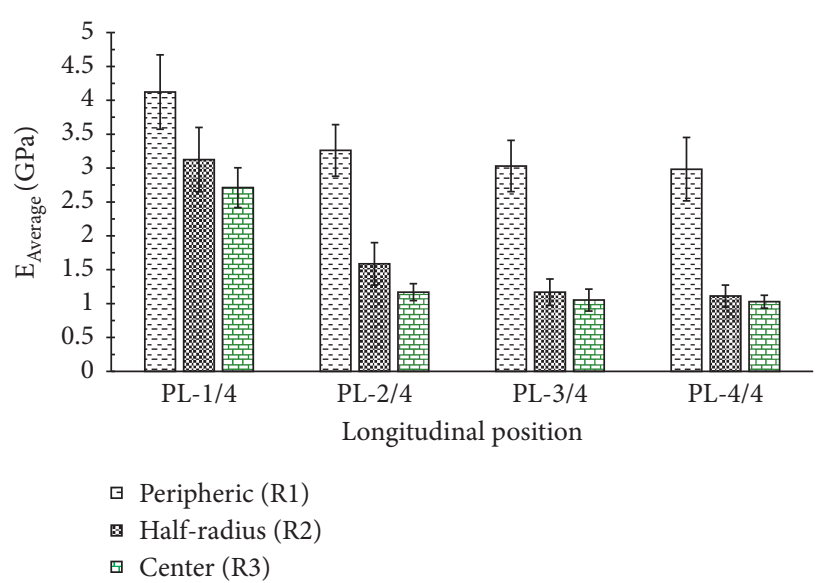

FIGURE 12: Distribution of Young's modulus in the bending test of RVP along the stem.

mechanical properties of the matrix resulting from the RVP may allow us to better consider the choice of the matrix to be used in the development of biodegradable composites based on RV fibers which would have better resistance in mechanical behavior and environment aspect.

\section{Conclusion}

In this study, the physicochemical and mechanical characterization of RVP is investigated. Samples were taken from twelve sampling zones along the stem and were characterized using the following techniques: the observation of images using an optical microscope and ImageJ software, SEM for chemical element analysis, Archimedes' principle for bulk density determination, and tensile tests and threepoint bending tests for Young's modulus determination. The conclusion of these experiments is as follows:

(i) Surface fraction values of RV fibers evolve from the center to the periphery in the radial position and vary between $35.80 \%$ and $54.50 \%$.

(ii) RVP is constituted essentially of carbon (C) and oxygen $(\mathrm{O})$ with a percentage of mass, respectively, in the intervals $51 \%-57 \%$ and $41 \%-48 \%$.

(iii) The bulk density values of RVP and RVP matrix increase from center to periphery and range, respectively, from $0.114 \mathrm{~g} / \mathrm{cm} 3$ to $0.343 \mathrm{~g} / \mathrm{cm} 3$ and $0.10 \mathrm{~g} / \mathrm{cm} 3$ to $0.46 \mathrm{~g} / \mathrm{cm} 3$.

(iv) Young's modulus of RVP and RVP matrix rises from the center to the periphery and varies, respectively, in the intervals $0.79 \mathrm{GPa}-3.23 \mathrm{GPa}$ and $1.20 \mathrm{GPa}-5.50 \mathrm{GPa}$.

(v) Young's modulus resulting from three-point bending tests for the RVP sample is enhanced from the center to the periphery of any cross section. The values ranged between $1.02 \mathrm{GPa}$ and $4.20 \mathrm{GPa}$.

(vi) Finally, the results obtained show that composites can be made based on RV fibers by observing the bulk density and Young's modulus of the RVP matrix which are comparable to polymer in order to 
make a better choice of matrix. In this perspective, we can consider the development of biocomposites based on RV fibers and the study of thermal properties of RVP.

\section{Data Availability}

The data used to support the findings of this study are available from the corresponding author upon request.

\section{Conflicts of Interest}

The authors declare that they have no conflicts of interest.

\section{Acknowledgments}

The authors would like to thank the Laboratory of Textile Physics and Mechanics (LPMT), University of HauteAlsace, France, for the help on the analysis of the fibers by the SEM (Jeol) and also for the dynamic tensile tests with the tensile machine (MTS 20/M) in this work.

\section{References}

[1] M. Ramesh, C. Deepa, L. R. Kumar, M. R. Sanjay, and S. Siengchin, "Life-cycle and environmental impact assessments on processing of plant fibres and its bio-composites: a critical review," Journal of Industrial Textiles, 2020.

[2] B. Mazian, A. Bergeret, J.-C. Benezet, and L. Malhautier, “A comparative study of the effect of field retting time on the properties of hemp fibres harvested at different growth stages," Fibers, vol. 7, no. 12, p. 108, 2019.

[3] M. Ramesh, C. Deepa, M. Tamil Selvan, and K. H. Reddy, "Effect of alkalization on characterization of ripe bulrush (Typha Domingensis) grass fiber reinforced epoxy composites," Journal of Natural Fibers, pp. 1-12, 2020.

[4] M. Ramesh, K. Palanikumar, and K. H. Reddy, "Plant fibre based bio-composites: sustainable and renewable green materials," Renewable and Sustainable Energy Reviews, vol. 79, pp. 558-584, 2017.

[5] M. Sandy and L. Bacon, "Tensile testing of raffia," Journal of Materials Science Letters, vol. 20, no. 6, pp. 529-530, 2001.

[6] P. K. Talla, A. Foudjet, and M. Fogue, "Statistical model of strength in flexion and size effect on the failure of Raphia vinifera L. (Arecacea)," Journal of Bamboo and Rattan, vol. 4, no. 4, pp. 335-342, 2005.

[7] T. N. R. Sikame, D. Ndapeu, D. Nkemaja et al., "Study of the viscoelastic behaviour of the Raffia vinifera fibres," Industrial Crops and Products, vol. 124, pp. 572-581, 2018.

[8] E. Njeugna, N. S. Tagne, J. Y. Drean, D. Fokwa, and O. Harzallah, "Mechanical characterization of raffia fibres from Raphia vinifera," International Journal of Mechanics Structural, vol. 3, no. 1, pp. 1-17, 2012.

[9] T. N. R. Sikame, E. Njeugna, M. Fogue, J. Y. Drean, and D. Fokwa, "Study of water diffusion through raffia vinifera fibres of the stem from Bandjoun-Cameroon: case of drying kinetics," Research Journal of Applied Sciences, Engineering and Technology, vol. 6, no. 19, pp. 3547-3558, 2013.

[10] N. R. Sikame Tagne, E. Njeugna, M. Fogue, J. Y. Drean, A. Nzeukou, and D. Fokwa, "Study of water absorption in Raffia vinifera fibres from Bandjoun, Cameroon," The Scientific World Journal, vol. 2014, Article ID 912380, 11 pages, 2014.
[11] E. T. Mbou, E. Njeugna, A. Kemajou, N. R. Sikame, and D. Ndapeu, "Modelling of the water absorption kinetics and determination of the water diffusion coefficient in the pith of raffia vinifera of Bandjoun, Cameroon," Advances in Materials Science and Engineering, vol. 2017, Article ID 1953087, 12 pages, 2017.

[12] P. K. Talla, T. Tekougnening, J. R. Ebale, E. Tangka, and A. Foudjet, "Statistical model of strength in compression of Raphia vinifera L. (Arecacea)," Journal of Bamboo and Rattan, vol. 3, no. 3, pp. 229-235, 2004.

[13] P. K. Talla, F. B. Pelap, M. Fogue et al., "Nonlinear creep behavior of Raphia vinifera L. (Arecacea)," International Journal of Mechanics and Solids, vol. 2, no. 1, pp. 1-11, 2007.

[14] P. K. Talla, J. S. Mabekou, M. Fogue et al., "Non-linear creep behavior of Raphia vinifera L. arecacea under flexural load," International Journal of Mechanics and Solids, vol. 5, no. 2, pp. 151-172, 2010.

[15] E. Foadieng, M. Fogue, and P. K. Talla, "Effect of the span length on the deflection and the creep behavior of raffia bamboo vinifera L. arecacea beam," International Journal of Mechanics and Solids, vol. 7, no. 2, pp. 153-167, 2012.

[16] T. N. R. Sikame, N. Ebénézer, N. Dieunedort et al., "Investigation of the physical and mechanical properties of Raffia vinifera fibers along the stem," Journal of Natural Fibers, vol. 14, no. 5, pp. 621-633, 2017.

[17] T. Nganya, "Intérêt d'utilisation d'isolants locaux dans l'habitation au Cameroun," Doctoral dissertation, Thèse doctorat, ENSP de Yaoundé, Yaounde, Cameroon, 2000.

[18] E. Foadieng, P. K. Talla, G. B. Nkamgang, and M. Fogue, "Study of the thermal properties of Raffia Bamboo vinifera L. Arecaceae," Advances in Materials Science and Engineering, vol. 2017, Article ID 9868903, 10 pages, 2017.

[19] N. Venkatachalam, P. Navaneethakrishnan, and T. P. Sathishkumar, "Characterization of novel Passiflora foetida natural fibers for paper board industry," Journal of Industrial Textiles, 2016.

[20] D. V. Hegde, M. C. Bhavanishankar, G. G. Kariyappa et al., "Studies on physical properties of wine palm and Roselle natural fibers," Journal of Natural Fibers, vol. 16, no. 8, pp. 1166-1176, 2019.

[21] R. S. Odera, O. D. Onukwuli, and C. U. Atuanya, "Characterization of the thermo-microstructural analysis of Raffia palm fibers proposed for roofing sheet production," Journal of Minerals and Materials Characterization and Engineering, vol. 3, no. 4, p. 335, 2015.

[22] A. Saravanakumaar, A. Senthilkumar, S. S. Saravanakumar, M. R. Sanjay, and A. Khan, "Impact of alkali treatment on physico-chemical, thermal, structural and tensile properties of Carica papaya bark fibers," International Journal of Polymer Analysis and Characterization, vol. 23, no. 6, pp. 529-536, 2018.

[23] ASTM-D3800-99, Standard Test Method for Density of HighModulus FIbers, ASTM International, West Conshohocken, PA, USA, 2005.

[24] B. A. Amel, M. T. Paridah, R. Sudin, U. M. K. Anwar, and A. S. Hussein, "Effect of fiber extraction methods on some properties of kenaf bast fiber," Industrial Crops and Products, vol. 46, pp. 117-123, 2013.

[25] O. K. Owolarafe, M. T. Olabige, and M. O. Faborode, "Physical and mechanical properties of two varieties of fresh oil palm fruit," Journal of Food Engineering, vol. 78, no. 4, pp. 1228-1232, 2007.

[26] N. Ranjbar, S. Talebian, M. Mehrali, C. Kuenzel, H. S. Cornelis Metselaar, and M. Z. Jumaat, "Mechanisms of interfacial bond 
in steel and polypropylene fiber reinforced geopolymer composites," Composites Science and Technology, vol. 122, pp. 73-81, 2016.

[27] ASTM D3822-01, Standard Test Method for Tensile Properties of Single Textile Fibers, ASTM International, West Conshohocken, PA, USA, 2014.

[28] M. K. Hossain, M. R. Karim, M. R. Chowdhury et al., "Comparative mechanical and thermal study of chemically treated and untreated single sugarcane fiber bundle," Industrial Crops and Products, vol. 58, pp. 78-90, 2014.

[29] I. S. Musanif and A. Thomas, "Effect of alkali treatments of physical and mechanical properties of coir fiber," Chemical and Materials Engineering, vol. 3, no. 2, pp. 23-28, 2015.

[30] N. Martin, P. Davies, and C. Baley, "Comparison of the properties of scutched flax and flax tow for composite material reinforcement," Industrial Crops and Products, vol. 61, pp. 284-292, 2014.

[31] C. Baley, C. Goudenhooft, P. Perré, P. Lu, F. Pierre, and A. Bourmaud, "Compressive strength of flax fibre bundles within the stem and comparison with unidirectional flax/ epoxy composites," Industrial Crops and Products, vol. 130, pp. 25-33, 2019.

[32] ASTM D790-07, Standard Test Methods for Flexural Properties of Unreinforced and Reinforced Plastics and Electrical Insulating Materials, ASTM International, West Conshohocken, PA, USA, 2007.

[33] L. Brancheriau, H. Bailleres, and D. Guitard, "Comparison between modulus of elasticity values calculated using 3 and 4 point bending tests on wooden samples," Wood Science and Technology, vol. 36, no. 5, pp. 367-383, 2002.

[34] L. Gurau, M. C. Timar, M. Porojan, and F. Ioras, "Image processing method as a supporting tool for wood species identification," Wood and Fiber Science, vol. 45, no. 3, pp. 303-313, 2013.

[35] Y. Yuan, M. P. Hays, P. R. Hardwidge, and J. Kim, "Surface characteristics influencing bacterial adhesion to polymeric substrates," RSC Advances, vol. 7, no. 23, pp. 14254-14261, 2017.

[36] L. Poorter, I. McDonald, A. Alarcón et al., "The importance of wood traits and hydraulic conductance for the performance and life history strategies of 42 rainforest tree species," New Phytologist, vol. 185, no. 2, pp. 481-492, 2010.

[37] K. Ziemińska, M. Westoby, and I. J. Wright, "Broad anatomical variation within a narrow wood density range-a study of twig wood across 69 Australian angiosperms," PLoS One, vol. 10, no. 4, 2015.

[38] H. Ku, H. Wang, N. Pattarachaiyakoop, and M. Trada, “A review on the tensile properties of natural fiber reinforced polymer composites," Composites Part B: Engineering, vol. 42, no. 4, pp. 856-873, 2011.

[39] V. Placet, A. Day, and J. Beaugrand, "The influence of unintended field retting on the physicochemical and mechanical properties of industrial hemp bast fibres," Journal of Materials Science, vol. 52, no. 10, pp. 5759-5777, 2017.

[40] L. R. Schimleck, J. L. M. Matos, R. Trianoski, and J. G. Prata, "Comparison of methods for estimating mechanical properties of wood by NIR spectroscopy," Journal of Spectroscopy, vol. 2018, Article ID 4823285, 10 pages, 2018.

[41] L. Yan, N. Chouw, and K. Jayaraman, "Flax fibre and its composites-a review," Composites Part B: Engineering, vol. 56, pp. 296-317, 2014.

[42] S. Hamdan, M. R. Rahman, I. Jusoh, and H. A. Wahid, “"Dynamic Young's modulus and moisture content of tropical wood species across sap, median, and internal wood regions," BioResources, vol. 13, no. 2, pp. 2907-2915, 2018.

[43] C. Baley, "Analysis of the flax fibres tensile behaviour and analysis of the tensile stiffness increase," Composites Part A: Applied Science and Manufacturing, vol. 33, no. 7, pp. 939948, 2002.

[44] M. Cai, H. Takagi, A. N. Nakagaito et al., "Influence of alkali treatment on internal microstructure and tensile properties of abaca fibers," Industrial Crops and Products, vol. 65, pp. 2735, 2015.

[45] J. M. Berthelot, Mécanique des matériaux et Structures Composites, pp. 15-48, Institut Supérieur des Matériaux et Mécaniques Avancés, LeMan, France, 2010. 